\title{
Research on Food Security Platform based on the Internet of Things (IOT) and Software-as-a-Service (SaaS) Model
}

\author{
Tao Qu ${ }^{1, a^{*}}$ and Hongyu $\mathrm{Yu}^{2, \mathrm{~b}}$ \\ ${ }^{1}$ School of Electronics \& Information Engineering University of Technology Liaoning \\ Liaoning, Jinzhou, China \\ ${ }^{2}$ Modern Educational Technology Center Jinzhou Teacher's Training College \\ Liaoning, Jinzhou, China \\ a54333928@qq.com, b156241142@qq.com
}

Keywords: Food safety; IOT; SaaS.

\begin{abstract}
Food safety problems related to the beneficial to the people's livelihood. The Internet of things (IOT) is an important part of the rising information technology, which is a software application model of software services based on the internet of things. In this paper, food security platform based on the Internet of Things (IOT) and Software-as-a-Service (SaaS) Model is proposed. The internet of things system with collecting food industry chain supervises each link of source to the table, which can effectively strengthen food safety. SaaS realizes synchronization of platform, promotion and constantly renews traceability technology of food safety.
\end{abstract}

\section{Introduction}

Currently, China has become the world's largest food market. Food industry has become one of the important pillars of the national economy, which has maintained a growth rate of more than $20 \%$ over the past 10 years. Chinese has entered high-incidence season of food safety. Recently food safety accidents happened at home and abroad has warmed us again and again that food safety has become a major problem which affects the overall situation. Thus, effects of food security on the economy, society, life are more and more widespread and profound. It is necessary to guarantee food safety and need a key. In this paper, IOT and SaaS are combined with to structure the food security platform, which are applied with the field of food security. It is a new idea and breakthrough to solve the problem of food safety.

\section{The Internet of Things Technology}

The Internet of things (IOT)[1-4] concept is proposed in 1999, which is a huge social information system consisted of perception layer, network layer, application layer. It is related to national economy, society and life, which is huge industrial chain. IOT has a complicated structure, which mainly contain three parts: the first part is perception layer, which collect information with smart card, RFID, identification code, sensor and so on; the second part is network layer, which is used to transmitting by the wireless network, mobile network, fixed network, the internet, radio, television network and so on; the third part is application layer, the information is processed, controlled and decided in this layer, it operates and completes to achieve recognition and perception between things to things and people to things. It seems intelligent. Compared with internet, the connection range of IOT is greater, which expands to things and achieve things to things or people. It comes into being a database which contains hundreds of millions things and people, can collect and store physics together with suppositional information. Through the analysis and decision, it completes the evolution from information to knowledge, and then intelligently command, control, and achieve the ability to handle and solve 
problems. Therefore, IOT is a simple network concept by no means, it is more like information system of a fusion between variety applications and the vast social services. Obviously, IOT makes the food supply chain management method of control area of the quality and safety of "third party" realizing, so as to realize the qualitative leap for the food quality and safety control. At the same time, because IOT manages the production and living in a more precise and dynamic way, the moral risk is avoided to some extent in the food supply chain. Chinese development level of IOT technology, has significant influence and laid the foundation for China's first use of network technology to design the control system of food safety in the world. Key techniques in the Internet of things is shown as Fig. 1

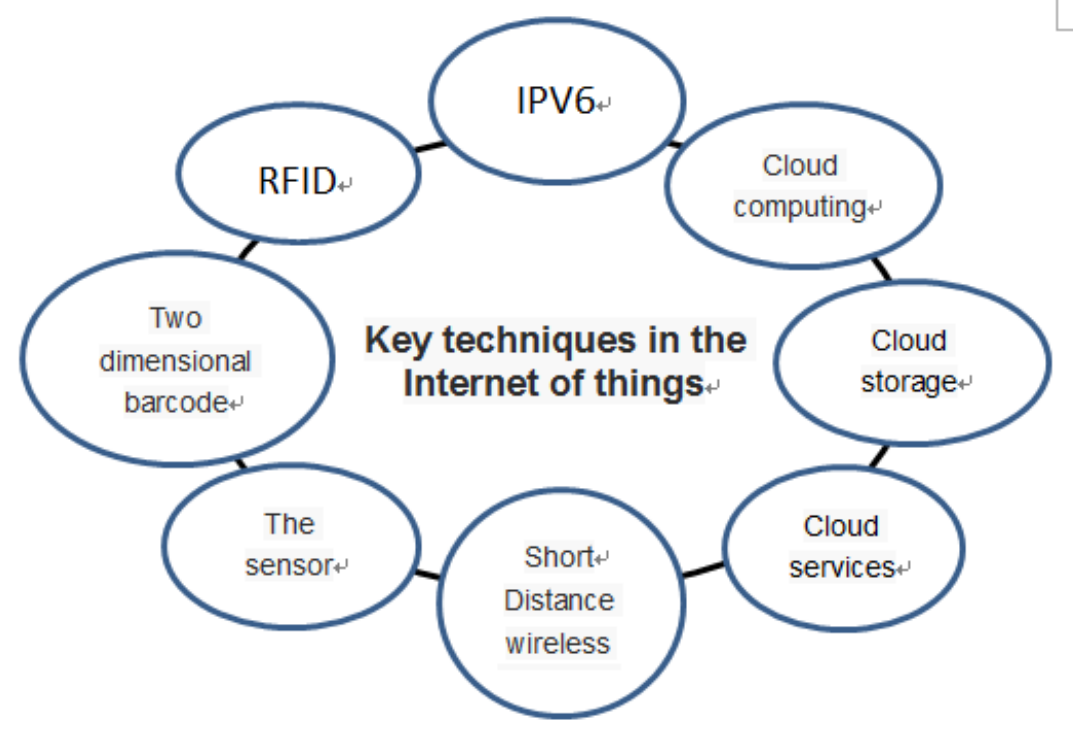

Figure 1. Key techniques in the Internet of things

\section{SaaS Platform based on Global Data Synchronization Network (GDSN)}

Global data synchronization network(GDSN)[5-8] is the standard of the global environment based on an automated. GDSN makes the data stability and ongoing synchronization, so that all trading partners to maintain consistency of their data in the system at the same time. In the supply chain each link of the trading partners can be provided accessing service through the GDSN authentication data pool. Especially, the food supply chain is planned to use the model of vertical integration industrial chain. It can better achieve synchronization of data and guarantee the effect of integration. It is better to real-time monitoring on the environment and business situation from the perspective of the overall situation analysis and real-time problem solving, which make the works and tasks being completed through multilateral cooperation to remote and completely changing the entire food control mode of operation.

GDSN data synchronization process is divided into five parts:

Data Acquisition and Upload. Products and company information are uploaded to the data pool by the seller (or other data provider).

Data registration. The key data set is then sent to the GS1 global registry[9].

Data Subscription Request. Purchaser side (or other data receiver) subscribe to a sale of GLN, product classification (GPC), the target market or GTIN to obtain the corresponding product and company information by serving his data pool.

Data Publishing. Sales data pool will publish the whole commodity information and partner information to the pool of purchaser. 
Data Acknowledgement. Then the purchaser sends a confirmation message to the sales side and informs the sales side of accepting or not in addition to a simple answer.

\section{Food Safety Platform based on IOT and SaaS}

Owing to the continuous development of IOT and SaaS technology. The paper proposes the construction and operation of supply chain network platform based on GDSN and IOT, which the main chain enterprises as the core, providing support for software[10] and technical services to the suppliers and customers of the supply chain SaaS model, construction a real-time, high efficiency, safety and food safety platform.

Application of technology of food safety in the platform of IOT mainly has following several aspects[11-15]:

Natural Environmental Factors Monitoring and Alarm System. Monitoring the natural environment plays a very important role in the food safety platform. Monitoring the environment of our application of IOT, we set the corresponding sensor in the required position. remotely through changes in the parameters of the sensor, we can know the change of the natural environment, and early warns system by setting the threshold. IOT automatically alarming through IOT, food security platform will be the timely detection of problems, issues and search it. We set the environment parameter which contain real-time collection of temperature, humidity and light signal, soil temperature, $\mathrm{CO} 2$ concentration, leaf wetness, dew point temperature, automatically open or close the specified device. We can according to user requirements to monitor comprehensive agricultural ecological information facilities at any time for processing in order to automatic control and intelligent management. The temperature sensor signal is gathered, data is transmitted via wireless signal transceiver module and remotely achieved control of greenhouse temperature and humidity.

We also set up the water quality monitoring station, which is not affected by the thunder and lightning storms and other severe weather. People know about water quality of each monitoring waters tough the control room computer. And once a certain waters was unexpected pollution, relevant personnel immediately will receive information on mobile phone. We use the intelligent environment-friendly products which can achieve continuous real-time monitoring and remote control of water quality, and timely grasp of major river section water to forecast major river basin water pollution incidents.

Logistics Risk Monitoring and Early Warning. Intelligent logistics create a set of information display, e-commerce, logistics distribution, warehousing management, financial pledge, park security, customs and other functions as one of the food area integrated information service platform. With the function integration, comprehensive efficiency information service platform is as the main development idea, e-commerce, online transactions, as the main form of trade. which integrates information service platform construction of a high standard, high grade, and financial pledge, security, customs and other functions for the interface, and can provide one-stop integrated information service for food production customer and management personnel.

Implementation of Food Safety Traceability System of Food Safety Platform. Food traceability system which is based on RFID technology, network technology and database technology, achieve information fusion, query, monitoring. It provide every piece of goods safety, food composition and the inventory control decision making to achieve food security early warning mechanism for each stage of production and distribution process to the final consumption fields. RFID technology has always been in food safety link, which includes production, processing, circulation, consumption of each link, and strictly control the entire process to establish the system of food safety control of a complete supply chain. It comes into being various open-loop applications of the food enterprises from production to sales in order to providing quality assured food to the society. It can ensure the high the quality of data 
communication in the supply chain, completely transparent management of food source tracing and food supply chain in the food production area.

In the main chain type supply chain SaaS food safety platform model, participated enterprise can not only supply chain collaboration with main chain enterprise and its control mechanism, but also collaborate with other enterprise platform. Broken only core enterprise cooperation way before, participated enterprise can also use the platform for internal business management, information e-commerce operation and comprehensive. When more and more enterprises use the platform, it would come into being the supply chain network from a single supply chain.

In the platform model, entities involved mainly contain SaaS software service provider, SaaS platform service provider, main chain enterprises and chain enterprise supply chain network. As the public platform based on GDSN, the SaaS software service provider is responsible for providing technical support and cooperation. The platform has consistency in data structure, architecture and so on, so that the main chain type supply chain network platform. So enterprises which supply chain network platform not only cooperate with all the users within the supply chain collaboration, but also cooperate with other platform for business cooperation. in generally, chief chain enterprises are ability to control and a higher position in the industry.

\section{Conclusions}

At the present stage an important livelihood issues is food safety problems in China. This paper presents model food safety platform based on IOT and SaaS software platform mode, to avoid the dispersion of food industry alone Information service in SaaS mode realize the network service application system and the networking between the overall interconnection. To lay the foundation for an in-depth perception, extension of the service network system to the development direction of the application of more deep.

\section{Acknowledgements}

Thank those people who helped me in silence, their valuable advice that my thesis can be completed smoothly.

\section{References}

[1] Wang Baoyun (College of Automation,Nanjing University of Posts and Telecommunications, Nanjing 210003, China);Review on internet of things[J];Journal of Electronic Measurement and Instrument;2009-12.

[2] The Application Investigation and Discussion of Internet of Things in Agriculture[A];[C];2010

[3] Han Zhen,Qu Shasha, The Role IOT Plays on the Logistics System Management and the Prospects of the Logistics System Based on the IOT[A];[C];2010

[4] Sui Wen,Tang Xiaochun, Study on Traceability System of Livestock Products for the 2008 Olympic Games[J];Food Science;2008-08

[5] Yu Pingxiang,Wu Yuanmei:Transactions of the Chinese Society of Agricultural Engineering,2008,24(7):132-136

[6] S. Yin, X. Li, H. Gao, O. Kaynak, Data-based techniques focused on modern industry: An overview,IEEE Transactions on Industrial Electronics,62(1):657-667, 2015.

[7] LI Mengxun,Liu Hongzhi: Journal of Food Science and Technology ,2011,29(2),P54-58 
[8] S. Yin, Z. Huang, Performance monitoring for vehicle suspension system via fuzzy positivistic $\mathrm{C}$-means clustering based on accelerometer measurements, IEEE/ASME Transactions on Mechatronics, 20(5):2613-2620, 2015.

[9] S. Yin, X. Zhu, O. Kaynak, Improved PLS focused on key performance indictor related fault diagnosis, IEEE Transactions on Industrial Electronics, 62(3):1651-1658, 2015.

[10] Yu Pingxiang, Wu Yuanmei: Transactions of the Chinese Society of Agricultural Engineering,2008,24(7)p132-136

[11] S. Yin, O. Kaynak, Big data for modern industry: challenges and trends, Proceedings of the IEEE, 102(3):143-146, 2015.

[12] Sun Qibo,Liu Jie: Journal of Beijing University of Posts and Telecommunications,2010,33(3)p1-9

[13] Dun Wentao, Xia Bin: Modern Agricultural Science and Technology,2012(24)p216-221.

[14] WEI Xiao-xiao Journal of Anhui Agricultural Sciences ,2011,39(24):15150-15152

[15] S. Yin, X. Zhu,?Intelligent particle filter and its application on fault detection of nonlinear system, IEEE Transactions on Industrial Electronics, 62(6):3852-3861, 2015. 